\title{
When Synchronizing to Rhythms Is Not a Good Thing: Modulations of Preparatory and Post-Target Neural Activity When Shifting Attention Away from On-Beat Times of a Distracting Rhythm
}

\author{
Assaf Breska ${ }^{1}$ and Leon Y. Deouell ${ }^{1,2}$ \\ ${ }^{1}$ Department of Psychology, Hebrew University of Jerusalem, Jerusalem 91905, Israel, and ${ }^{2}$ Edmond and Lily Safra Center for Brain Sciences, Hebrew \\ University of Jerusalem, Jerusalem 91904, Israel
}

Environmental rhythms potently drive predictive resource allocation in time, typically leading to perceptual and motor benefits for on-beat, relative to off-beat, times, even if the rhythmic stream is not intentionally used. In two human EEG experiments, we investigated the behavioral and electrophysiological expressions of using rhythms to direct resources away from on-beat times. This allowed us to distinguish goal-directed attention from the automatic capture of attention by rhythms. The following three conditions were compared: (1) a rhythmic stream with targets appearing frequently at a fixed off-beat position; (2) a rhythmic stream with targets appearing frequently at on-beat times; and (3) a nonrhythmic stream with matched target intervals. Shifting resources away from on-beat times was expressed in the slowing of responses to on-beat targets, but not in the facilitation of off-beat targets. The shifting of resources was accompanied by anticipatory adjustment of the contingent negative variation $(\mathrm{CNV})$ buildup toward the expected off-beat time. In the second experiment, off-beat times were jittered, resulting in a similar CNV adjustment and also in preparatory amplitude reduction of beta-band activity. Thus, the CNV and beta activity track the relevance of time points and not the rhythm, given sufficient incentive. Furthermore, the effects of task relevance (appearing in a task-relevant vs irrelevant time) and rhythm (appearing on beat vs off beat) had additive behavioral effects and also dissociable neural manifestations in target-evoked activity: rhythm affected the target response as early as the P1 component, while relevance affected only the later N2 and P3. Thus, these two factors operate by distinct mechanisms.

Key words: cognitive control; EEG; oscillations; rhythms; temporal predictions

Significance Statement

Rhythmic streams are widespread in our environment, and are typically conceptualized as automatic, bottom-up resource attractors to on-beat times-preparatory neural activity peaks at rhythm-on-beat times and behavioral benefits are seen to on-beat compared with off-beat targets. We show that this behavioral benefit is reversed when targets are more frequent at off-beat compared with on-beat times, and that preparatory neural activity, previously thought to be driven by the rhythm to on-beat times, is adjusted toward off-beat times. Furthermore, the effect of this relevance-based shifting on target-evoked brain activity was dissociable from the automatic effect of rhythms. Thus, rhythms can act as cues for flexible resource allocation according to the goal relevance of each time point, instead of being obligatory resource attractors.

\section{Introduction}

In many situations in daily life, such as listening to speech and music or viewing biological motion, goal-relevant stimuli appear rhythmically. The brain can use this temporal regularity to predict the time of future stimuli, maximize preparedness at rhythm-on-beat times, and facilitate behavioral responses to on-beat events, relative to off-beat events (Jones et al., 2002; Nobre et al., 2007). In electroencephalographic (EEG) recordlished reagents/analytic tools; A.B. analyzed data; A.B. and L.Y.D. wrote the paper.

This research was funded by a grant from the Israel Science Foundation to L.Y.D. We thank Eden Krispin and Guy Romach for assisting in data collection.
The authors declare no competing financial interests.

Correspondence should be addressed to Assaf Breska, the Department of Psychology, the Hebrew University of Jerusalem, Mount Scopus, Jerusalem 91905, Israel. E-mail: assaf.breska@gmail.com.

DOI:10.1523/JNEUROSCI.4619-15.2016

Copyright $\odot 2016$ the authors $\quad 0270-6474 / 16 / 367154-13 \$ 15.00 / 0$ 
ings, this is associated with prestimulus adjustment of preparatory potentials [contingent negative variation $(\mathrm{CNV})$ ] and alpha- and beta-band oscillatory activity (Alegre et al., 2003; Praamstra et al., 2006; Rohenkohl and Nobre, 2011; Fujioka et al., 2012; Breska and Deouell, 2014), and with modulations of target-evoked neural processing in sensory and response selection stages (Jones et al., 2002; Correa et al., 2005; Doherty et al., 2005; Mathewson et al., 2010; Sanabria et al., 2011; Rohenkohl et al., 2012). It was suggested that these effects result from entrainment: low-frequency neural oscillations, correlated with fluctuations between periods of high and low neural sensitivity to the input, become phase aligned to the external rhythm such that periods of high sensitivity coincide with on-beat times (Barnes and Jones, 2000; Schroeder and Lakatos, 2009). Importantly, alignment of high preparation with on-beat times also occurs incidentally with exposure to taskirrelevant rhythms (Sanabria et al., 2011; Fujioka et al., 2012; Mento et al., 2013; Breska and Deouell, 2014).

However, increasing preparation at rhythm-on-beat times may be detrimental for current goals when the rhythmic streams are distracting. For example, when exposed to police lights while driving, it is essential to oppose the attraction of resources to on-beat times to enable continuous vigilance. In some situations, it may even be beneficial to shift resources away from on-beat times to reduce the distracting effect of rhythms. Previous studies showed that when targets follow a single preparatory stimulus (S1-S2 paradigms), the level of preparation, as reflected in response times, follows the probability distribution of target intervals (hazard function; Nobre et al., 2007). This effect was also associated with adjustments of the CNV and oscillatory brain activity (Trillenberg et al., 2000; Cravo et al., 2011). However, given the automatic attraction of resources to on-beat times (Breska and Deouell, 2014), it is not clear to what extent shifting resources away from on-beat times is possible, and what neural mechanisms are involved in such reorganization of preparation.

Rhythmic inhibition as a means to ignore a distracting rhythm (e.g., an external conversation that overshadows the conversation of interest) was previously demonstrated when two streams were interleaved. This was expressed in synchronization of fluctuations in neural sensitivity with the attended stream, but not with the unattended stream (Lakatos et al., 2008; Besle et al., 2011), and in attenuated neural responses and diminished behavioral performance for the ignored stream stimuli (Lakatos et al., 2013; O'Connell et al., 2014). However, the question remains whether resources can be shifted away from on-beat times of a single rhythm, when no other rhythm is available to entrain to. Furthermore, it is not clear whether such shifting is possible only when an expected off-beat event is known to appear at a fixed phase lag relative to the rhythmic stream, which allows the shifting to be mediated by interval-timing mechanisms (with the rhythmic stimuli serving as triggers for a putative timer).

The present study investigated these questions by presenting task-adverse rhythmic streams. In two EEG experiments, visual rhythmic streams were followed by targets that had high probability to appear off beat, making it counterproductive to align resources with the rhythm. In the first experiment, the timing of off-beat targets was fixed relative to the rhythm, while in the second experiment it was jittered. We tested whether there would be a behavioral benefit or cost for rhythm-on-beat times, and whether the CNV, alpha band, and beta band activity, as well as target-evoked responses, would be adjusted to the locus of tem- poral attention or detrimentally aligned with the task-irrelevant on-beat times.

\section{Materials and Methods}

\section{Participants}

Fifty Hebrew University students participated in two experiments (Experiment 1: 26 participants; 17 females; mean age, 23.9 years; Experiment 2: 24 participants; 16 females; mean age, 24.3 years) in return for course credit or monetary compensation. All participants reported normal or corrected-to-normal vision and normal color vision. Participants reported having no professional musical training and did not play a musical instrument during the 3 years before the experiment. The study was approved by the institutional ethics committee, and all participants provided written informed consent.

\section{Stimuli and design}

Experimental stimuli were filled color circles (diameter, $6^{\circ}$ ), each presented for $100 \mathrm{~ms}$. In each trial, a stream of five, six, or seven (uniform probability) white stimuli were presented, followed by a green target, to which participants had to respond as quickly as possible with a button press. In each experiment there were the following three conditions: "attend-on-beat", "attend-off-beat", and "random" (Fig. 1). In the first two conditions, the white stimuli appeared rhythmically, with an identical stimulus-onset asynchrony (SOA) of $850 \mathrm{~ms}$ (fast-stream trials) or $1400 \mathrm{~ms}$ (slow-stream trials). The random condition was used to control for the foreperiod effect [i.e., decrease in reaction time (RT) due to the passage of time; Niemi and Näätänen, 1981]. In this condition, the white stimuli did not appear rhythmically, but were jittered around the SOA of the corresponding rhythmic condition (fast-stream trials, 650-1050 ms; slow-stream trials, $1200-1600 \mathrm{~ms} ; 100 \mathrm{~ms}$ steps; uniform distribution). In each experimental block, trials were of the same condition and stream SOA.

The extent to which it was beneficial to prepare for rhythm-on or off-beat times was manipulated between experimental conditions by changing the distribution of target SOAs relative to the last white stimulus.

Experiment 1 (fixed off-beat SOA). Each block included 40 trials. The target SOA in "on-beat" trials was identical to that of the preceding rhythm ( $850 \mathrm{~ms}$ for fast rhythm and $1400 \mathrm{~ms}$ for slow rhythm), while in "off-beat" trials it was shorter (500 ms for fast rhythm and $850 \mathrm{~ms}$ for slow rhythm). In the "attend-on-beat" condition, $80 \%$ of the trials were on-beat trials and $20 \%$ were off-beat. In the "attend-off-beat" condition, only $20 \%$ of the trials were on beat, and $80 \%$ of the trials were off beat. In the "random" condition, in $50 \%$ of the fast-stream trials the target appeared at an interval of $850 \mathrm{~ms}$ from the previous stimuli, while in the other $50 \%$ there was an interval of $500 \mathrm{~ms}$. In slow-stream trials, the intervals were 1400 and $850 \mathrm{~ms}$. Thus, target intervals in the random condition were identical to the corresponding rhythmic conditions.

Experiment 2 (jittered off-beat SOA). The target SOA in on-beat trials was identical to that of the preceding rhythm, whereas in offbeat trials it was one of four shorter SOAs $(300,400,500$, and $600 \mathrm{~ms}$ for fast rhythm; and 400, 600, 800, and $1000 \mathrm{~ms}$ for slow rhythm). In the attend-on-beat condition ( 40 trials per block), $80 \%$ of the trials were on-beat trials, and $20 \%$ were off-beat trials ( $5 \%$ for each SOA). In the attend-off-beat condition ( 54 trials per block), only one-ninth of the trials were on-beat trials, and eight-ninths of the trials were off-beat trials (two-ninths for each SOA). In the random condition (40 trials per block), the target SOA was identical to the on-beat SOA in $20 \%$ of the trials, and to each of the four off-beat SOAs in another $20 \%$ of the trials.

\section{Procedure}

The experiment was conducted in a sound-attenuated chamber (model C-26, ECKEL). The stimuli were presented at the center of a 17 inch CRT screen ( $100 \mathrm{~Hz}$ refresh rate; G75f, ViewSonic) on a gray background (viewing distance, $90 \mathrm{~cm}$ ). Stimulus presentation and response acquisition were handled using the Psychophysics toolbox (Brainard, 1997; Pelli, 1997) for MATLAB (version 7.5.0, MathWorks). Participants conducted 12 blocks with the order FFF- 
A

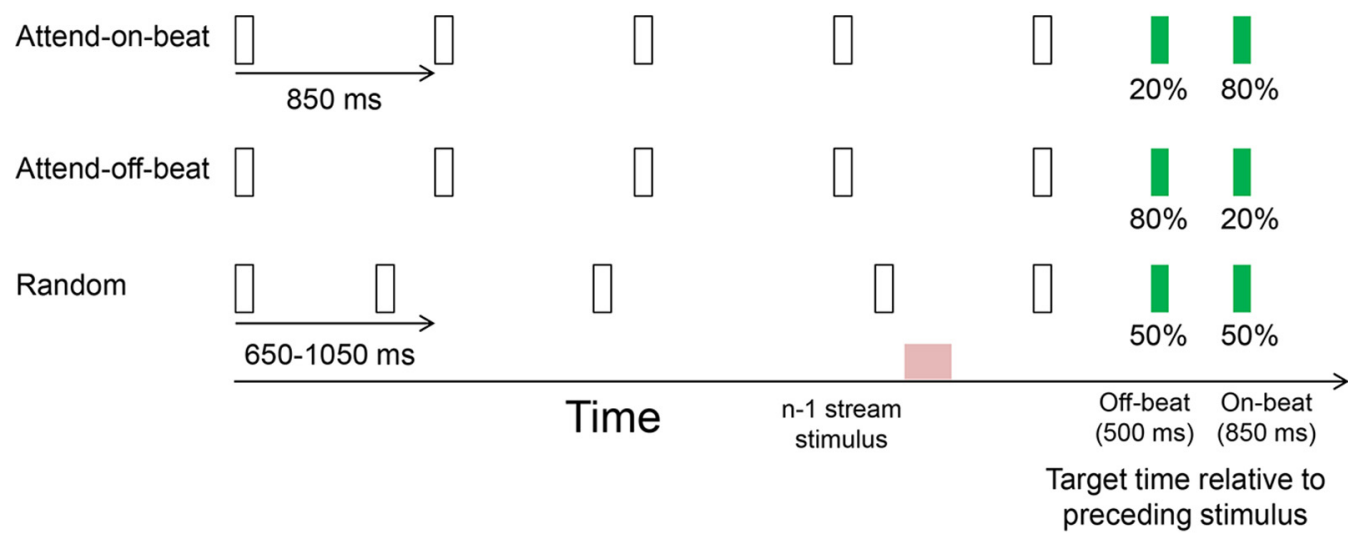

B

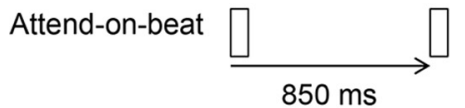

Attend-on-beat
Attend-on-beat

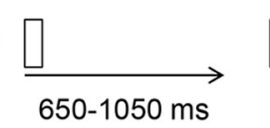

Attend-on-beat

$650-1050 \mathrm{~ms}$

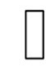

$\square$

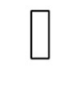

$\square$
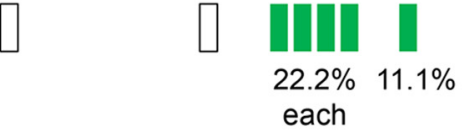

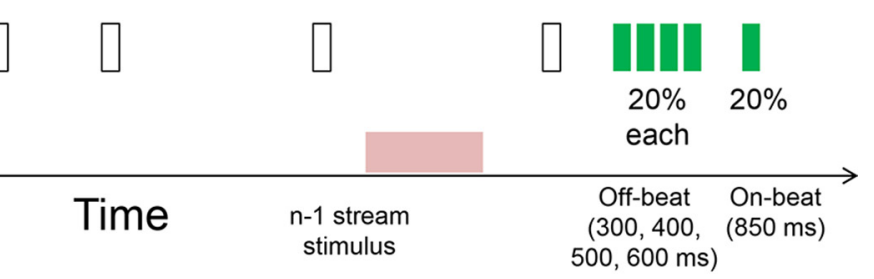

Target time relative to preceding stimulus

Figure 1. Experimental paradigm. $\boldsymbol{A}$, Experiment 1. Participants detected targets (green stimulus) that followed a stream of visual stimuli (white stimuli). The percentage under the targets stimuli indicates the probability that a target appeared at that time point in the corresponding condition. In the attend-on-beat condition, the stream was rhythmic with targets more probable on beat; in the attend-off-beat condition, the stream was rhythmic with targets more probable at a fixed off-beat position than at an on-beat position; and in the random condition, the stream intervals were jittered, making the stream less rhythmic, and targets had identical probability to appear at matched intervals to those of the rhythmic conditions. $\boldsymbol{B}$, Experiment 2. Task design was identical to that of Experiment 1, except for having four equally probable possible times for off-beat targets. In both experiments, only the fast-stream condition (short-stream SOA with an average stream interval of $850 \mathrm{~ms}$ ) is presented for simplicity. Pink patches indicate the interval for analysis of anticipatory brain activity before the expected off-beat target time, between the $n-1$ and the $n$ stream stimuli (demonstrated here between fourth and fifth stimuli).

SSSFFFSSS or SSSFFFSSSFFF (counterbalanced across subjects), where $\mathrm{F}$ represents fast-stream blocks, and $\mathrm{S}$ represents slow-stream blocks. Within each FFF or SSS triplet, the order of conditions was random block, attend-on-beat block and attend-off-beat block. At the beginning of each block, participants were instructed about the probabilities of target timing, and were encouraged to use this knowledge to be prepared for the target. Participants then performed a practice session consisting of at least eight trials if it was the first time a condition had been encountered, and at least four trials otherwise.

\section{Behavioral analysis}

For each participant, trials were discarded if the RT was $>3$ SDs larger than the mean RT, calculated separately for each condition and stream SOA. Trials with RTs shorter than $50 \mathrm{~ms}$ were also discarded. RTs were subjected to an omnibus repeated-measures ANOVA with factors condition (random/attend-on-beat/attend-off-beat), stream SOA (fast stream/slow stream), and target SOA. In Experiment 1, the target SOA factor had two levels (on beat/off beat), while in Experiment 2, it had five levels (one on beat and four off beat). Wherever the sphericity assumption was violated, we report Greenhouse-Geisser corrected $p$ values and uncorrected degrees of freedom. To test the costs and benefits of attentional shifting beyond the foreperiod effect
(Niemi and Näätänen, 1981), we directly compared each of the attend-off-beat and attend-on-beat conditions with the random condition with separate contrasts for each time interval (the on-beat interval and each of the off-beat intervals). In Experiment 2, the comparisons between the four off-beat times and the random condition were corrected using the Bonferroni method.

In Experiment 1, we also examined the combined effect of rhythmicity (appearing on-beat/off-beat) and task relevance (appearing at the relevant/irrelevant time point), by analyzing the conditions in which the target appeared at $850 \mathrm{~ms}$ (on-beat targets in fast streams and off-beat targets in slow streams) in the attend-on-beat and attend-off-beat conditions using a $2 \times 2$ ANOVA. This analysis was not conducted in Experiment 2 for two reasons. First, different types of attention presumably operate at on-beat and off-beat times. When on-beat times were relevant, attention could be focused in time at a specific time point, whereas when off-beat times were relevant, attention had to be sustained throughout the entire interval. In Experiment 1, attention could be focused at both on-beat and off-beat times, as the latter was fully predictable. Second, the temporal uncertainty in Experiment 2 induced a foreperiod effect, making it difficult to compare (Niemi and Näätänen, 1981) the responses to the $850 \mathrm{~ms}$ targets in the fast (on-beat) and slow (off-beat) streams. 


\section{EEG recording and preprocessing}

EEG was recorded continuously from 64 preamplified $\mathrm{Ag} / \mathrm{AgCl}$ electrodes using an Active 2 system (BioSemi), mounted on an elastic cap according to the extended 10-20 system. Four additional electrodes were placed on the outer canthi of the right and left eyes, and above and below the center of the right eye to track electro-oculographic activity, and electrodes were placed on the left and right mastoids, near the tip of the nose. The EEG signal was sampled at a rate of $1024 \mathrm{~Hz}$ (24 bits/channel) with an on-line antialiasing $204 \mathrm{~Hz}$ low-pass filter.

EEG preprocessing was conducted using BrainVision Analyzer 2.0 (Brain Products), using the following pipeline: referencing the nose electrode; high-pass filtering using a zero-shift Butterworth filter with a cutoff of $0.1 \mathrm{~Hz}$ (24 dB/octave); correction of ocular artifacts using independent component analysis (Jung et al., 2000) based on typical scalp topography and time course; and the elimination of epochs that contained other artifacts, defined as absolute activity of $>100 \mu \mathrm{V}$ or a change of $>100 \mu \mathrm{V}$ in a $200 \mathrm{~ms}$ interval.

\section{EEG analysis}

Preparatory activity. Analyses of preparatory activity were conducted in the two rhythmic conditions during the interval between the last stimulus of the preparatory stream (position $n$ ) and the preceding stimulus (position $n-1$ ). This was the latest interval in which there was a full rhythmic cycle uninterrupted by an early off-beat target. Thus, in streams with five white stimuli, the interval of interest was between the fourth and fifth stimuli; in streams with six white stimuli, the interval of interest was between the fifth and sixth stimuli; and in streams with seven white stimuli, the interval of interest was between the sixth and seventh stimuli (Fig. 1, demonstrated for a stream with five white stimuli). As participants did not know how many white stimuli would precede the target, we assumed that they were forming predictions for the target during all of these intervals. The data were segmented into epochs of -200 to $1600 \mathrm{~ms}$ relative to the $n-1$ rhythm stimulus for slow rhythms, and into epochs of -200 to $1050 \mathrm{~ms}$ relative to the $n-1$ rhythm stimulus for fast rhythms.

The CNV is a buildup of negative potential that is observed in frontocentral scalp electrodes (above motor and premotor cortex) when expecting an impending event (Walter et al., 1964). For the CNV analysis, the data were rereferenced to the average of the left and right mastoids, and averaged across a cluster of frontocentral electrodes (F1, Fz, F2, FC1, FCz, FC2, C1, Cz, and C2; Miniussi et al., 1999; Correa and Nobre, 2008). The epochs were averaged separately for the attend-on-beat and attendoff-beat conditions, and for fast and slow rhythms. A period of $100 \mathrm{~ms}$ preceding the $n-1$ stimulus was used as the baseline. In goal-relevant rhythms, the CNV builds up to a peak approximately at the time of the next rhythmic stimulus, resulting in a steeper buildup when the expected interval is shorter (Praamstra et al., 2006; Breska and Deouell, 2014). First, to verify the presence of this effect, we compared the CNV amplitude in the attend-on-beat condition between fast and slow rhythms, over an interval of $500-850 \mathrm{~ms}$ after the $n-1$ stimulus, expecting larger negativity in fast streams. Next, we tested whether the CNV would build up faster when shifting resources to an earlier off-beat time point than to the on-beat time. To test this, we compared the CNV amplitude between the attend-on-beat and attend-off-beat conditions during the last $200 \mathrm{~ms}$ before the expected off-beat target, across all possible target intervals (Experiment 1:300-500 and 650-850 ms after the $n-1$ stimulus for fast and slow rhythms, respectively; Experiment 2: 100-600 and 300-1000 $\mathrm{ms}$ after the $n-1$ stimulus for fast and slow rhythms, respectively). Note that a target never appeared in the analyzed intervals (it always followed the $n$ stimulus). If preparation builds up to an earlier time point, we would expect a more negative CNV amplitude in the attend-off-beat condition compared with the attend-on-beat condition.

Studies of goal-relevant rhythms found amplitude reduction of occipital alpha-band activity $(8-13 \mathrm{~Hz})$ and central beta-band activity $(14-24$ $\mathrm{Hz}$ ) just before or at the onset of a temporally expected target (Praamstra et al., 2006; Rohenkohl and Nobre, 2011; Fujioka et al., 2012; Breska and Deouell, 2014). We tested whether shifting resources away from on-beat times to off-beat times would be associated with amplitude reductions at off-beat times; that is, whether the amplitude at off-beat times will be reduced in the attend-off-beat condition relative to the attend-on-beat condition. Instantaneous amplitudes were extracted using a complex Morlet wavelet transform (1-30 Hz; $1 \mathrm{~Hz}$ steps; ratio between the central frequency and the standard deviation of the Gaussian-shaped wavelet in the frequency domain, 8). Additional margins of $2000 \mathrm{~ms}$ were added before and after each segment to absorb edge artifacts, and were later discarded from analysis. In contrast to the CNV analysis, we limited the analysis to the slow stream (with an SOA of $1400 \mathrm{~ms}$ ) to avoid the effect of the stimulus-evoked activity, which is smeared in time by the timefrequency decompositions. The resulting time-frequency representations were averaged across occipital electrodes for alpha-band analysis $\left(\mathrm{PO} 3 / \mathrm{PO} 4, \mathrm{PO} 7 / \mathrm{PO} 8, \mathrm{O}_{1} / \mathrm{O}_{2}\right)$ and across central electrodes for betaband analysis $(\mathrm{C} 1 / \mathrm{C} 2, \mathrm{C} 3 / \mathrm{C} 4, \mathrm{Cz})$. In these trials, epochs were averaged separately for the attend-on-beat and attend-off-beat conditions. A period of $200 \mathrm{~ms}$ preceding the $n-1$ stimulus was used as a baseline. The amplitude of oscillatory activity was compared between the attend-onbeat and attend-off-beat conditions at a window of 650-850 ms after the $n-1$ stimulus (just before when an off-beat target would appear in the rhythmic conditions of Experiment 1). If the perceptual resources are shifted to an earlier time point in the attend-off-beat condition, occipital alpha-band and central beta-band activity would be suppressed in offbeat times of the attend-off-beat condition, compared with off-beat times of the attend-on-beat condition.

Target-evoked responses. Target-evoked responses in Experiment 1 were analyzed in the two rhythmic conditions for targets with identical SOA of $850 \mathrm{~ms}$ that appeared on beat and off beat (on beat of fast-stream trials and off beat of slow-stream trials). The data were segmented into epochs extending from -200 to $800 \mathrm{~ms}$ relative to target onset, and averaged separately for the attend-on-beat and attend-off-beat conditions and for on-beat and off-beat targets. A period of $100 \mathrm{~ms}$ preceding the target ( -100 to 0$)$ was used as the baseline.

Regions of interest in electrode space were defined based on the spatial distributions of components observed in previous studies of temporal predictions (Miniussi et al., 1999; Doherty et al., 2005; Praamstra et al., 2006; Correa et al., 2008). The P1 component was analyzed at a cluster of occipital electrodes (O1, PO3, PO7, $\left.\mathrm{O}_{2}, \mathrm{PO} 4, \mathrm{PO} 8\right)$; the $\mathrm{N} 2$ component was analyzed at two separate clusters, one of midline-frontal electrodes $(\mathrm{Fz}, \mathrm{F} 1, \mathrm{~F} 2)$ and one of parietal electrodes (Pz, P1, P2); and the P3 was analyzed at a cluster of parietal electrodes (Pz, P1, P2). The amplitudes and latencies of the peaks of these components in the different conditions were estimated using the Jackknifing procedure (Miller et al., 1998; Kiesel et al., 2008), with corrections applied to statistical tests following the method of Ulrich and Miller (2001). The time intervals in which the peaks were detected were defined based on unbiased inspection of the average waveform across conditions (P1, 95-135 ms; N2, 240-280 ms; P3, 300-400 ms). The amplitude of each component was defined as the average of a $40 \mathrm{~ms}$ interval centered on the estimated peak latency. Matching the behavioral analysis, the synergistic effect of rhythmicity (appearing on-beat/off-beat) and of task relevance (appearing at the relevant/irrelevant time point) on the extracted amplitudes and latencies were analyzed using a $2 \times 2$ ANOVA.

\section{Results}

\section{Experiment 1}

Observers detected targets that followed a stream of visual stimuli, which could be rhythmic or nonrhythmic. Shifting resources away from rhythm-on-beat times was tested in the attend-off-beat condition, in which the stream was rhythmic, but the targets had low probability to coincide with the rhythm. In contrast, in the attend-on-beat condition, the stream was rhythmic, and the targets had high probability to coincide with the rhythm. In the random condition, the stream was not rhythmic, and the targets had identical probability to appear at intervals identical to the on-beat and off-beat intervals of the other conditions. The targets that appeared off beat with rhythms always appeared at a fixed SOA relative to the rhythm SOA, making it possible to explicitly predict their timing even though they were incongruous with the rhythmic sequence preceding the target. 


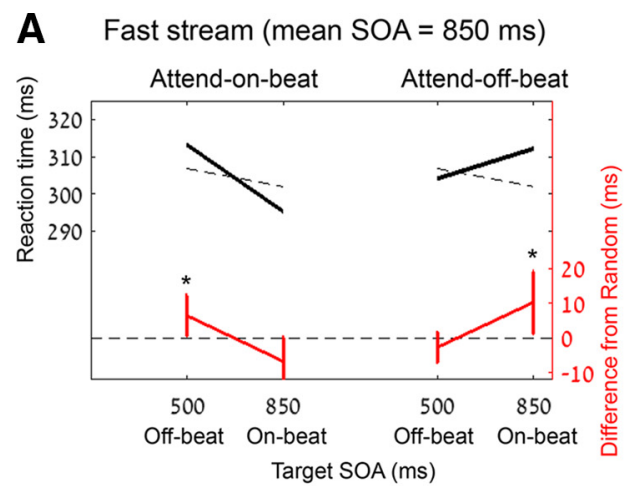

B Fast stream (mean SOA = $850 \mathrm{~ms}$ )

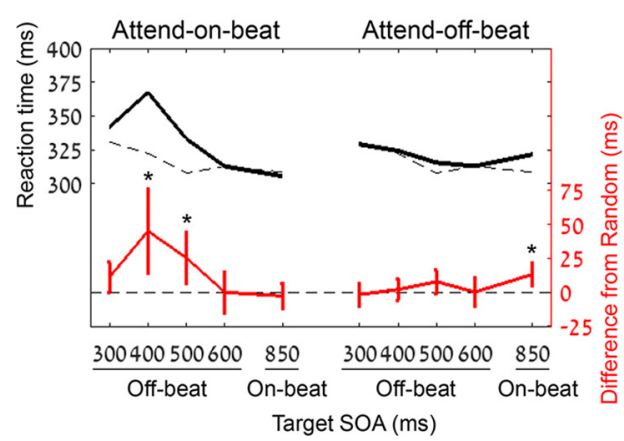

Slow stream (mean SOA = $1400 \mathrm{~ms}$ )

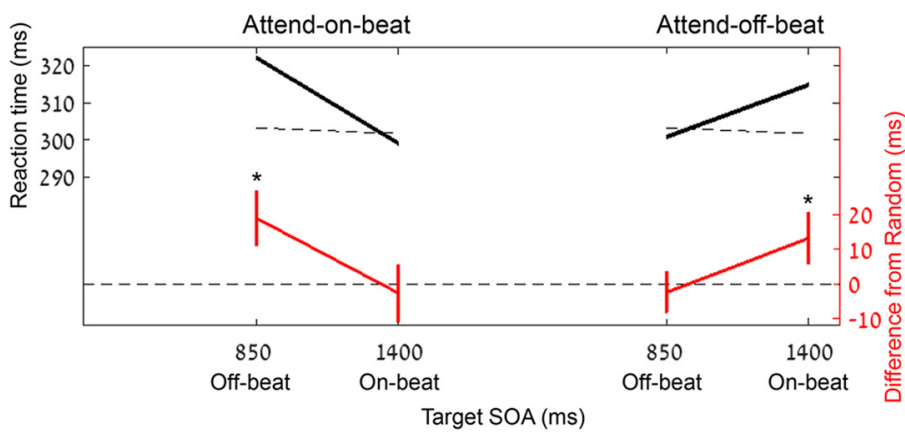

Slow stream (mean SOA $=1400 \mathrm{~ms})$

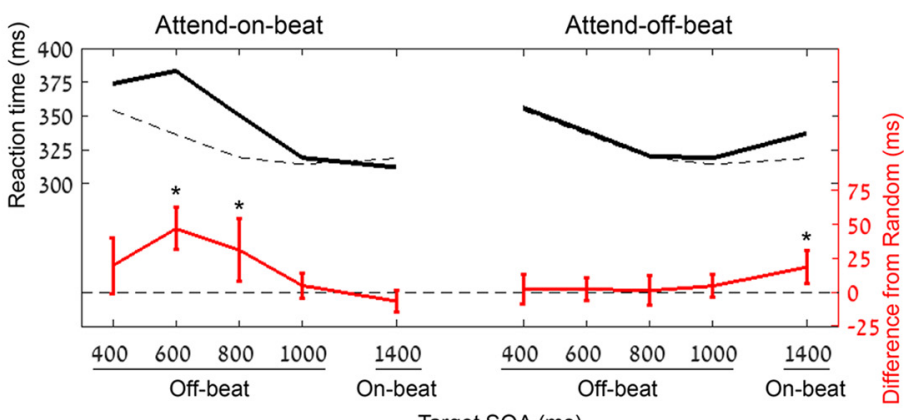

Target SOA (ms)

Figure 2. Behavioral consequences of shifting resources from rhythm-on-beat times to off-beat times. $A$, Experiment 1 (fixed off-beat time): mean reaction times for fast-stream (left) and slow-stream (right) trials at on-beat and off-beat target $\mathrm{SOAs}$, in the three experimental conditions. Black lines represent reaction times in the attend-on-beat and attend-off-beat conditions; broken gray lines represent the results of the random condition, which was used as a reference for both the attend-on-beat and attend-off-beat conditions. Red lines represent differences between each rhythmic condition and the corresponding random condition. $\boldsymbol{B}$, Mean reaction times in Experiment 2, in which off-beat times were jittered, for fast-stream (left) and slow-stream (right) trials at on-beat and off-beat target SOAs, in the three experimental conditions. The color scheme is the same as in $A$. For both experiments, error bars on red lines represent $95 \%$ confidence intervals for the difference. Stream SOA, mean interstimulus interval of the white stimuli stream; Target SOA, time (in ms) from the onset of the last white stimulus of the stream to the green target onset. Within each panel, significant differences $(p<0.05)$ from the corresponding random conditions are marked with an asterisk.

Table 1. Results of omnibus ANOVAs conducted on response times in each of the two experiments

\begin{tabular}{|c|c|c|c|c|c|c|c|c|}
\hline \multirow[b]{2}{*}{ Experimental factor } & \multicolumn{4}{|c|}{ Experiment 1} & \multicolumn{4}{|c|}{ Experiment 2} \\
\hline & df & $F$ & $p^{a}$ & $\eta_{p}^{2}$ & df & $F$ & $p^{a}$ & $\eta_{p}^{2}$ \\
\hline Condition & 2,50 & 2.16 & 0.13 & 0.08 & 2,46 & 17.04 & $3 \times 10^{-6^{*}}$ & 0.43 \\
\hline Target SOA & 1,25 & 2.86 & 0.1 & 0.1 & 4,92 & 25.03 & $1 \times 10^{-8^{*}}$ & 0.52 \\
\hline Condition $\times$ stream SOA & 2,50 & 2.78 & 0.08 & 0.1 & 2,46 & 0.11 & 0.86 & 0.01 \\
\hline Condition $\times$ target $\mathrm{SOA}$ & 2,50 & 30.04 & $2 \times 10^{-8^{*}}$ & 0.55 & 8,184 & 9.48 & $1 \times 10^{-8^{*}}$ & 0.29 \\
\hline Stream SOA $\times$ target $\mathrm{SOA}$ & 1,25 & 0.16 & 0.69 & 0.01 & 4,92 & 3.3 & $0.014^{*}$ & 0.13 \\
\hline
\end{tabular}

$\eta_{p}^{2}$ partial eta squared.

${ }^{a} p$ Value for the effect of the respective experimental factor. Significant effects are marked with an asterisk.

Response times

The effects of Condition (attend-on-beat/attend-off-beat/random), Target SOA (on-beat/off-beat), and Stream SOA (fast stream/slow stream) on response times were tested using a threeway ANOVA (Fig. 2A; Table 1, full ANOVA statistics). As expected, the effect of Target SOA interacted with Condition $(p=$ $2 \times 10^{-8}$ ), implying that preparation in time differed between conditions. To examine resource allocation in each condition, we performed two planned interaction contrasts comparing each of the rhythmic conditions to the random condition, followed by a simple effect analysis within each target SOA. Comparison of the attend-on-beat and random conditions revealed a significant interaction effect $\left(F_{(1,25)}=28.07, p=2 \times 10^{-5}, \eta_{p}^{2}=0.53\right)$, as follows: the attend-on-beat condition had slower responses to off-beat targets than the random condition $\left(t_{(25)}=4.97, p=\right.$
$4 \times 10^{-5}$, Cohen's $\left.d=0.99\right)$, but did not have faster responses to on-beat targets $\left(t_{(25)}=-1.31, p=0.2\right)$. Comparison of the attend-off-beat condition to the random condition also revealed a significant interaction $\left(F_{(1,25)}=13.39, p=0.0012, \eta_{p}^{2}=0.35\right)$. However, in contrast to the attend-on-beat condition, the attendoff-beat condition had slower responses to on-beat targets $\left(t_{(25)}\right.$ $=3.24, p=0.0034$, Cohen's $d=0.65)$, but did not have faster responses to off-beat targets $\left(F_{(1,25)}=-1.18, p=0.25\right)$. There were no other main effects or interactions (Table 1). We also examined whether the pattern of results was affected by the number of white stimuli in the stream (five, six, or seven). When including the stream length as a factor in the omnibus ANOVA, longer streams elicited shorter responses $\left(F_{(2,50)}=124.87, p=\right.$ $\left.4 \times 10^{-20}, \eta_{p}^{2}=0.83\right)$, especially in the long SOA streams. How- 
A Fast stream (mean stream $\mathrm{SOA}=850 \mathrm{~ms}$ )
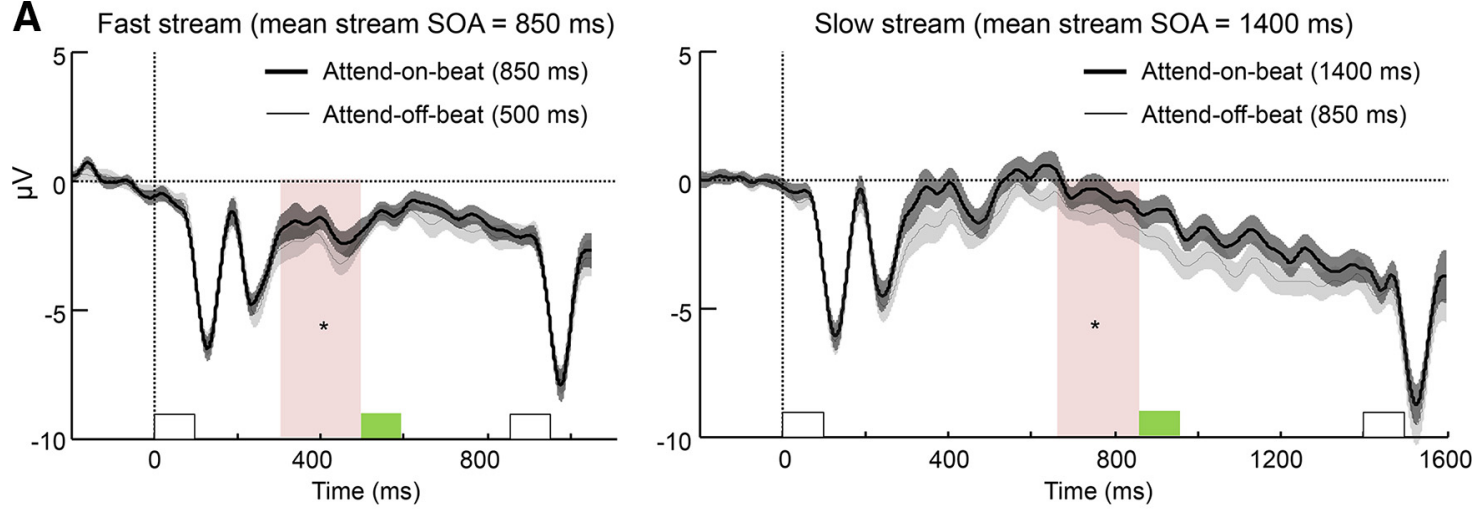

B Fast stream (mean stream SOA $=850 \mathrm{~ms}$ )
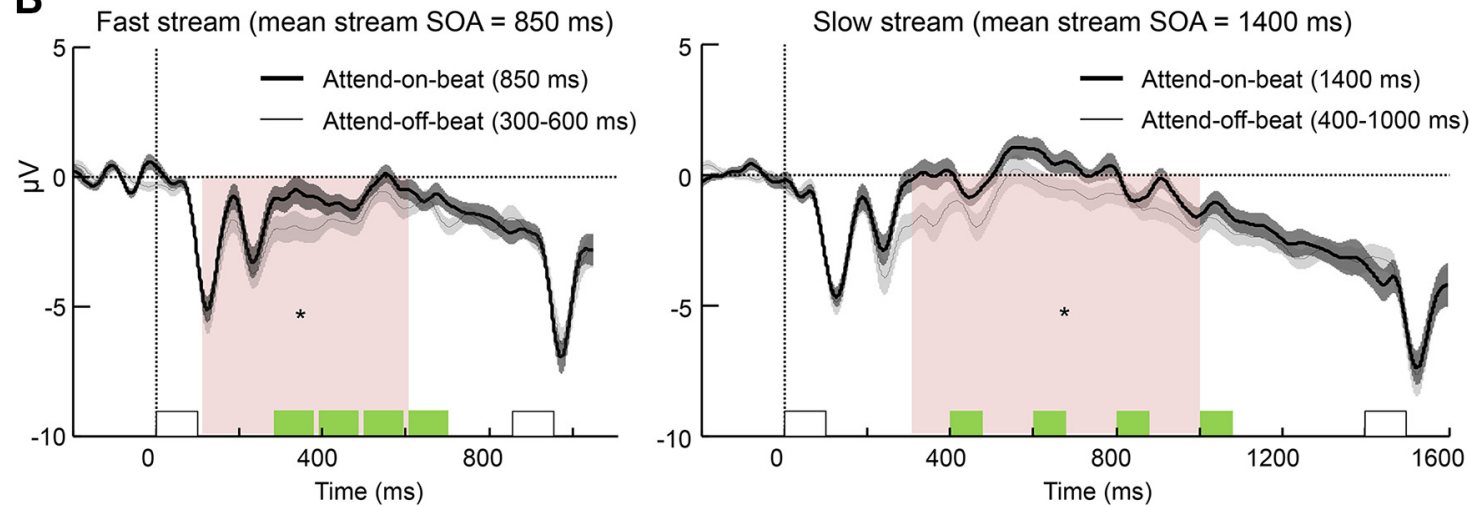

Figure 3. Modulation of the CNV by shifting resources away from rhythm-on-beat times to off-beat times. $A$, Group-averaged ERP waveforms (averaged across a nine-electrode frontocentral cluster) locked to the rhythm in the attend-on-beat (thick line) and the attend-off-beat (thin line) in Experiment 1, in which off-beat times were fixed, for fast (left) and slow (right) streams. $\boldsymbol{B}$, Same as $A$, for Experiment 2, in which off-beat times were jittered. White bars mark rhythmic stimuli at position $n$ (the last stimulus preceding the target, at time $=850 \mathrm{~ms}$ for fast stream and time $=$ $1400 \mathrm{~ms}$ for slow streams) and at position $n-1$ (at time $=0$ ). The green bar marks the optional times of the off-beat targets, which were relevant in the attend-off-beat condition. Note that a target was never actually presented in the analyzed interval. Error margins reflect the SE for the difference between the attend-on-beat and attend-off-beat conditions; pink background marks the predefined interval for analysis $\left({ }^{*} p<0.05\right)$.

ever, there was no three-way interaction among the factors Stream length, Condition, and Target SOA $\left(F_{(4,100)}=1.34, p=\right.$ $0.27)$. Critically, the significant interaction between Condition and Target SOA found across stream length was found also within each stream length separately (all values of $F_{(2,50)}>8.9$, all values of $p<0.01$ ), with responses in the attend-on-beat condition being faster for on-beat targets, and responses in the attendoff-beat condition being faster for off-beat targets. In summary, participants were indeed able to shift resources from on-beat times of task-adverse rhythms, but this was only expressed in a cost for on-beat time but not in a benefit to off-beat times.

Participants' ability to successfully shift resources away from on-beat times enabled the separation of validity effects of rhythm (appearing at on-beat vs off-beat time) and task relevance (appearing at relevant vs irrelevant time) on target processing. This was conducted for targets with the same SOA of $850 \mathrm{~ms}$, which were on beat in the fast rhythms and off beat in the slow rhythms, and could either be relevant or irrelevant based on the condition. A $2 \times 2$ ANOVA on RTs revealed a main effect of relevance $\left(F_{(1,25)}=36.51, p=3 \times 10^{-6}, \eta_{p}^{2}=0.59\right)$, with faster responses to targets appearing at relevant versus irrelevant times. Furthermore, there was no interaction between the two factors $\left(F_{(1,25)}=\right.$ $0.33, p=0.57)$, indicating that the relevance effect did not differ between targets that appeared on beat and off beat. However, even though resources were shifted to the relevant time point, there was still a main effect of rhythmicity $\left(F_{(1,25)}=5.23, p=\right.$ $\left.0.031, \eta_{p}^{2}=0.17\right)$, with faster responses to on-beat versus off-beat targets. The additivity of these two factors suggests that they operate through distinct mechanisms.

\section{Neurophysiology}

Preparatory potentials. The CNV, a negative potential building up at frontocentral electrodes (Walter et al., 1964), was observed in Experiment 1 in the interval between rhythmic stimuli in all rhythmic conditions (Fig. 3A). In the attend-on-beat condition, the CNV amplitude was more negative in fast compared with slow rhythms $\left(t_{(25)}=2.1, p=0.046\right.$, Cohen's $\left.d=0.42\right)$. This reflects faster $\mathrm{CNV}$ buildup as the next event is expected earlier, which is the typical modulation of the CNV by goal-relevant rhythms (Praamstra et al., 2006; Breska and Deouell, 2014). The crucial question was whether shifting resources away from rhythm-on-beat to off-beat times involved modulations of the $\mathrm{CNV}$, even though the streams were identical. To test this, we compared the attend-off-beat and the attend-on-beat conditions during the last interval of the rhythmic stream that did not terminate in the target, just before when an off-beat target would be expected. The CNV amplitude was more negative at this time in the attend-off-beat condition than in the attend-on-beat condition (fast rhythm: $t_{(25)}=2.17, p=0.04$, Cohen's $d=0.43$; slow rhythm: $t_{(25)}=2.17, p=0.04$, Cohen's $\left.d=0.43\right)$. Notably, in both the fast attend-on-beat condition and the slow attend-offbeat condition, subjects expected the target at exactly $850 \mathrm{~ms}$, and the $\mathrm{CNV}$ before this point was similar in these two conditions $t_{(25)}=0.3$; uncorrected $p=0.77 ; 95 \%$ confidence interval for 
the difference between conditions, -1.27 to $0.95 \mu \mathrm{V})$. Restricting the same analyses to the intervals between the fifth and sixth stimuli and between the sixth and seventh stimuli, but not the intervals between the fourth and fifth stimuli (because targets never actually appeared at the fifth position), yielded qualitatively similar results. Thus, the stage of preparation that is expressed in the CNV is not driven solely by the rhythm, but can adjust when off-beat times are relevant by preparing to peak at an earlier time point.

Time-frequency analysis. Previous studies found suppression of occipital alpha-band oscillations just before or at the time of a rhythmic stimulus in goalrelevant rhythms (Praamstra et al., 2006; Rohenkohl and Nobre, 2011; Breska and Deouell, 2014). In our data, there was a typical suppression of alpha oscillations $(8-13 \mathrm{~Hz})$ after the onset of a rhythmic stimulus, followed by rebound back to baseline levels (Fig. 4, left column). To test whether shifting resources away from rhythm-on-beat to off-beat times involved modulations of alpha activity, we compared the attend-off-beat and the attend-on-beat in the same interval as was tested for the CNV. This comparison was done in only the slow streams to avoid smearing due to target-evoked responses. This comparison did not reveal a significant decrease in amplitude in the interval just before the possible time of an off-beat target in the attend-off-beat condition $\left(t_{(25)}=-0.02, p=0.98\right)$.

The amplitude of beta-band activity in central sites typically decreases in anticipation of an upcoming rhythmic stimulus (beta suppression), followed by a rebound after stimulus presentation (Praamstra et al., 2006; Fujioka et al., 2012). Beta-band activity in both the attend-on-beat and attend-off-beat conditions followed this typical pattern of amplitude fluctuation (Fig. 4, right column). However, comparison of the attend-off-beat and the attend-on-beat conditions in the same interval, as was used for alpha-band activity, did not reveal any significant suppression of beta-band oscillations in the attendoff-beat condition in the interval just before the possible time of an off-beat target $\left(t_{(25)}=-0.41, p=0.69\right)$.

Target-evoked potentials. Using the same conditions as in the corresponding analysis of response times (identical target SOA of $850 \mathrm{~ms}$ ), we analyzed three event-related potentials (ERPs) that were previously found to be affected by rhythmic temporal prediction, the P1, the N2, and the P3 (Doherty et al., 2005; Correa et al., 2008; Breska and Deouell, 2014), for the synergistic effects of rhythmicity and task relevance. The $\mathrm{P} 1$ component is associated with early visual processing (Di Russo et al., 2002). Previous studies found increased amplitude of the P1 for targets that coincided with goal-relevant rhythms compared with those that deviated
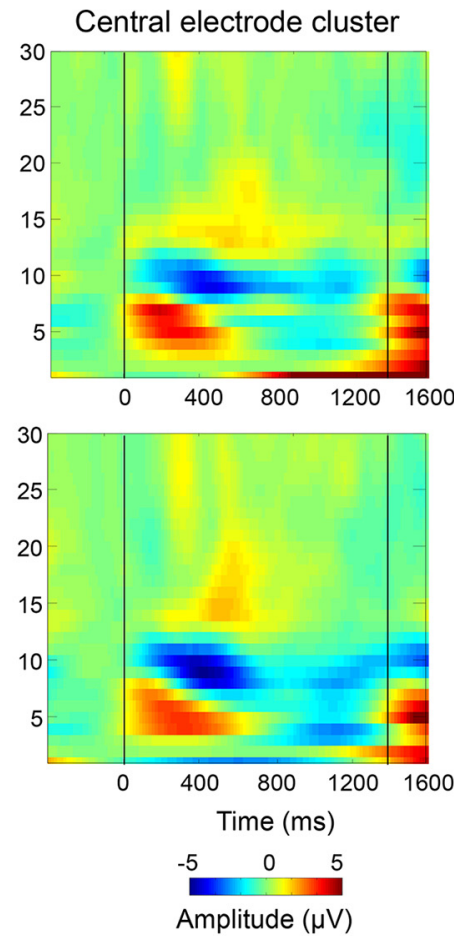

Central electrode cluster

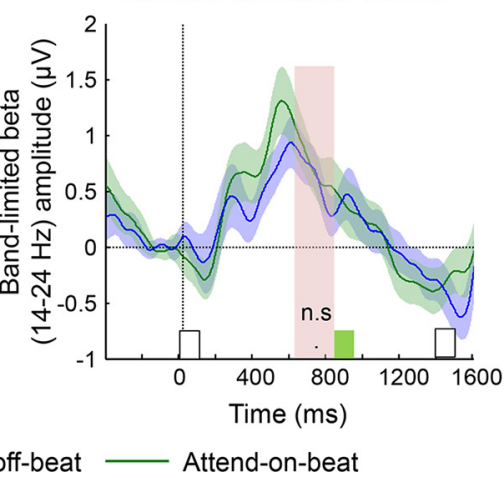

- Attend-off-beat — Attend-on-beat

Figure 4. Experiment 1: no modulation of alpha- or beta-band activity by shifting resources away from rhythm-on-beat times to a fixed off-beat time. $\boldsymbol{A}$, Group-averaged time-frequency representations in the two rhythmic conditions (top row, attend-offmark the onset of rhythmic stimuli at position $n$ (the last stimulus preceding the target, at time $=850 \mathrm{~ms}$ for fast streams and time $=1400 \mathrm{~ms}$ for slow streams) and at position $n-1$ (at time $=0)$. $\boldsymbol{B}$, Band-limited amplitude of occipital alpha $(8-13 \mathrm{~Hz}$, left tions. White squares mark rhythmic stimuli at position $n$ and at position $n-1$. Green squares mark the expected time of off-beat targets. Note that a target was never actually presented in the analyzed interval. Pink shading marks the predefined interval for analysis. Error margins reflect the SE for the difference between the attend-on-beat and attend-off-beat conditions.

from the rhythm (Doherty et al., 2005). Across conditions, we observed a visual $\mathrm{P} 1$ peaking in occipital sites $115 \mathrm{~ms}$ after target onset with typical occipital topography (Fig. 5A). A $2 \times 2$ ANOVA on the P1 amplitude revealed a main effect of rhythmicity $\left(F_{(1,25)}=5.12, p=0.033\right)$, with a more positive amplitude for on-beat targets than for off-beat targets, but no effect of relevance $\left(F_{(1,25)}=0.12, p=0.82\right)$ or interaction between rhythmicity and relevance $\left(F_{(1,25)}=0.02, p=0.76\right.$; Fig. $\left.5 B\right)$. No effects were observed for the P1 latency (all values of $F<$ 1). Thus, in contrast to the CNV, which was also affected by relevance, early visual responses were modulated by rhythmicity only.

Enhancement of the N2 component is typically observed in frontal sites when activating executive control, especially in the 

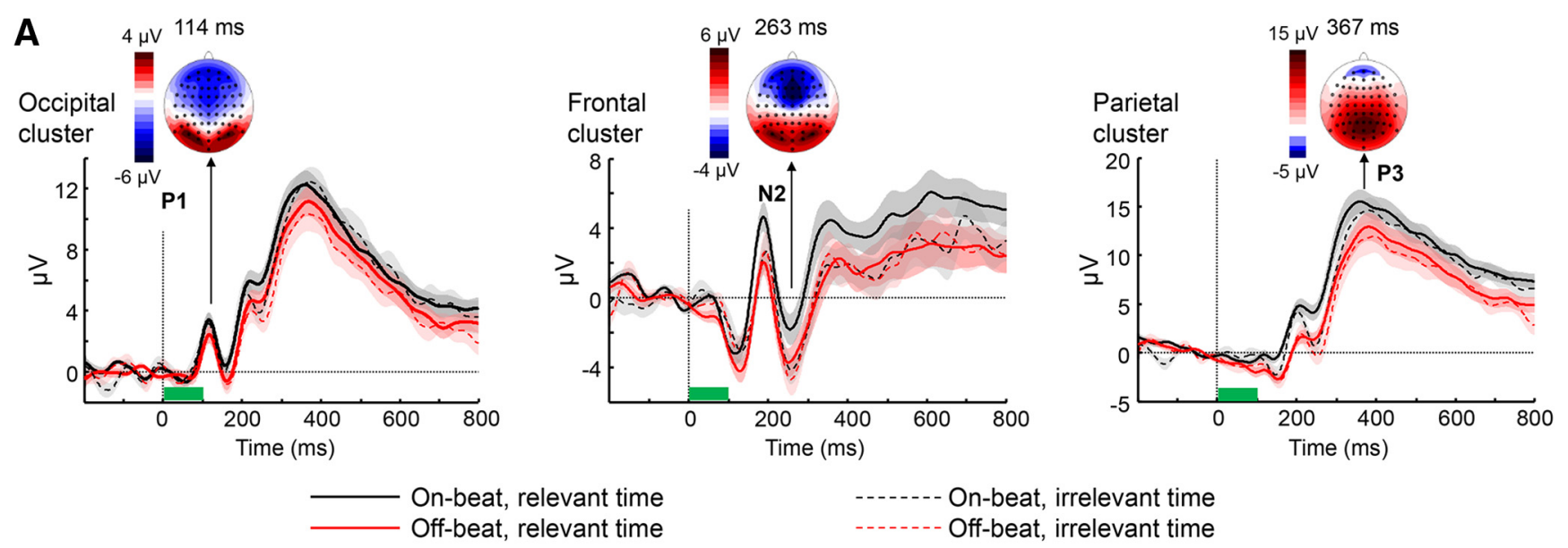

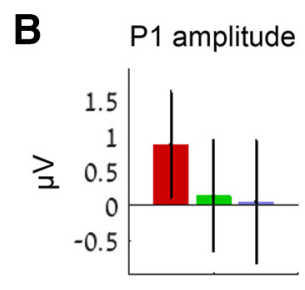

P1 latency

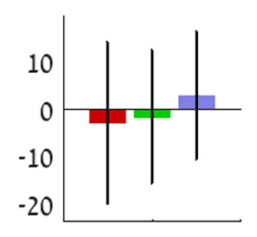

Rhythm effect (on-beat-off-beat)
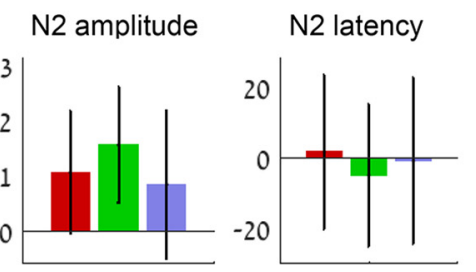

--- On-beat, irrelevant time -...- Off-beat, irrelevant time

Interaction effect (rhythm effect in relevant - rhythm effect in irrelevant)

Figure 5. Dissociable effect of target-evoked potentials by rhythm and relevance. $A$, Group-averaged ERP waveforms measured at three electrode clusters (left, occipital; middle, frontal; right, parietal) locked to the onset of targets (green bar), which appeared with an SOA of $850 \mathrm{~ms}$ from the preceding rhythmic stimulus, and could be either on beat or off beat relative to the rhythm (black and red colors, respectively), and could appear at a task-defined relevant or irrelevant time (solid and dashed lines, respectively). The three ERP components that were analyzed (P1, N2, and P3) are marked, along with scalp topographies at the time of the peak of each component (averaged across conditions and across a range of $\pm 10 \mathrm{~ms}$ ). Error margins reflect the SEM of each condition. $\boldsymbol{B}$, The effects of rhythm, relevance, and their interaction on the amplitude and latency of the ERP components. Bars represent the mean difference scores for the effect of each factor. Error bars reflect $95 \%$ confidence intervals.

face of conflict or the need for response inhibition (Kok, 1986; Kopp et al., 1996). A similar enhancement was also observed for deviation from goal-relevant rhythms in both frontal and parietal sites (Doherty et al., 2005; Correa et al., 2008). In our data, the N2 was observed in frontal sites between 240 and $280 \mathrm{~ms}$ after target onset. A $2 \times 2$ ANOVA on the N2 amplitude in frontal sites revealed a main effect of rhythmicity $\left(F_{(1,25)}=4.46, p=0.045\right)$, with a more negative amplitude for off-beat than for on-beat targets, and no significant interaction between rhythmicity and relevance $\left(F_{(1,25)}=1.52, p=0.23\right)$. However, in contrast to the P1 component, there was also an effect of relevance $\left(F_{(1,25)}=\right.$ 9.64, $p=0.0046$ ), with a more negative $\mathrm{N} 2$ amplitude elicited by targets appearing at relevant compared with irrelevant times. Similar results were obtained for parietal sites (rhythmicity effect: $F_{(1,25)}=10, p=0.0041$; relevance effect: $F_{(1,25)}=22.44$, $p=7 \times 10^{-5}$; interaction: $\left.F_{(1,25)}=1.58, p=0.22\right)$, but no effects were observed for the N2 latency at any cluster (all values of $F<1$ ).

The $\mathrm{P} 3$ component is associated with stimulus evaluation and response selection (Donchin and Coles, 1988). Previous studies found increased amplitude and earlier latency of the P3 for targets that coincided compared with those that deviated from goalrelevant rhythms (Correa et al., 2008, Doherty et al., 2005, Breska and Deouell, 2014). In our data, the P3 was maximal in parietal sites, peaking in the time range between 300 and $400 \mathrm{~ms}$ after target onset. Analysis of the P3 amplitude revealed a main effect of rhythmicity, with larger amplitudes for on-beat compared with off-beat targets $\left(F_{(1,25)}=11.07, p=0.0027\right)$, which did not interact with relevance $\left(F_{(1,25)}=0.01, p=0.99\right)$. Although there were larger amplitudes for relevant compared with irrelevant targets, the effect of relevance was only marginally significant $\left(F_{(1,25)}\right.$ $=3.18, p=0.09$ ). However, analysis of the P3 peak latencies revealed strong effects for both rhythmicity (on-beat earlier than off-beat: $F_{(1,25)}=10.19, p=0.0038$ ) and relevance (relevant earlier than irrelevant: $\left.F_{(1,25)}=6.76, p=0.015\right)$, with no interaction $\left(F_{(1,25)}=0.01, p=0.88\right)$.

When analyzing the combined effects of rhythm and task relevance, we aimed to match the target SOA between conditions. Therefore, on-beat targets were taken from fast rhythms, while off-beat targets were taken from slow rhythms, such that the target onset was always $850 \mathrm{~ms}$ after the preceding stimulus. However, it could be claimed that, with this strategy, the sustained difference between responses to on-target and off-beat targets was due to the different rhythmic contexts. That is, the off-beat targets were embedded in rhythms with a lower frequency than the on-beat targets $(0.71$ vs $1.18 \mathrm{~Hz})$, putatively generating a slower oscillation that shifts the waveform. To test this, we repeated this analysis, but this time we matched the rhythmic context (stream SOA) between conditions, rather than the target SOA. For this purpose, we collapsed across all on-beat targets (from slow and fast rhythms) and all off-beat targets (from slow and fast rhythms) and repeated the analysis. If the sustained difference resulted from the different rhythmic contexts, it should have been eliminated in this analysis. However, this was not the case, with on-beat targets still eliciting a more 
positive waveform as early as the $\mathrm{P} 1$ window $\left(F_{(1,25)}=10.47, p=\right.$ $0.0034)$.

\section{Experiment 2}

The findings of Experiment 1 indicate that it is possible to use rhythms to shift resources away from on-beat times of a taskadverse rhythm, even in the absence of a secondary interleaved rhythmic stream to engage to. The goal of Experiment 2 was to examine whether shifting resources away from on-beat times is restricted to when the expected event appears at a fixed off-beat time, as in Experiment 1. In such conditions, resource shifting in time may be explained by forming a focused temporal prediction based on memorizing the interval between the rhythmic stimuli and the expected off-beat time using interval-timing mechanisms (Coull et al., 1998; Miniussi et al., 1999; Macar and Vidal, 2004). Alternatively, they may be explained by oscillatory entrainment (Barnes and Jones, 2000; Lakatos et al., 2008, 2013; Schroeder and Lakatos, 2009) to an imagined, phase-shifted stream, such that periods of high neural excitability are aligned with off-beat times, and periods of low neural excitability with on-beat times (Lakatos et al., 2013). This latter alternative should be expressed in a reversal of the phase of delta activity in the attend-off-beat condition relative to the on-beat condition. We inspected our data for such phase reversal by filtering the EEG signal measured in occipital electrodes to the delta range $(0.3-2 \mathrm{~Hz})$, but did not find found a phase shift of delta activity between the attend-on-beat and the attend-off-beat conditions. It should be noted, though, that interpreting the phase of delta activity in paradigms like ours, which may induce CNV for every stimulus, is tenuous. This question could be addressed more directly in future studies by applying paradigms that disentangle the CNV and delta phase (Kayser et al., 2015). To examine resource shifting away from on-beat times independently of a fixed off-beat time, Experiment 2 followed the design of Experiment 1 but presented off-beat targets at one of several possible intervals.

\section{Response times}

As in Experiment 1, the effects of Condition (attend-on-beat/ attend-off-beat/random), Target SOA (five possible intervals: one on beat, four off beat), and Stream SOA (fast stream/slow stream) on response times were tested using a three-way ANOVA (Fig. 2B; Table 1, full ANOVA statistics). Most importantly, there was a significant interaction between target SOA and condition $\left(p=1 \times 10^{-8}\right.$, Table 1), indicating that, as in Experiment 1, the distribution of preparation in time differed between conditions. Planned comparison between the attend-on-beat and random conditions revealed a significant interaction between Target SOA and condition $\left(F_{(4,92)}=7.51, p=0.012, \eta_{p}^{2}=0.25\right)$. A simple effects analysis showed that the attend-on-beat condition had slower responses for off-beat targets [only for those that appeared at the second off-beat interval $\left(t_{(23)}=4.46\right.$, Bonferroni-corrected $p=0.0007$, Cohen's $d=0.93)$ and the third off-beat interval $\left(t_{(23)}\right.$ $=2.96$, Bonferroni-corrected $p=0.028$, Cohen's $d=0.62)]$, but not faster responses for on-beat targets $\left(t_{(23)}=1.06\right.$, uncorrected $p=0.3$ ). Planned comparison between the attend-off-beat and random conditions revealed a significant interaction between Target SOA and condition $\left(F_{(4,92)}=3.87, p=0.018, \eta_{p}^{2}=0.14\right)$, as follows: responses for on-beat targets were delayed $\left(t_{(23)}=\right.$ 3.53 , Bonferroni-corrected $p=0.007$, Cohen's $d=0.74$ ), but no facilitated responses were found for off-beat targets at any offbeat SOA (all values of $t_{(23)}<1.3$, all uncorrected p values $>0.2$ ). There was a main effect of condition, with overall slower responses in the attend-on-beat condition $\left(p=3 \times 10^{-6}\right)$, seem- ingly due to the strong delay for off-beat targets in this condition. Also, responses were faster overall for fast compared with slow streams $\left(p=4 \times 10^{-4}\right)$ and for long compared with short target SOAs $\left(p=1 \times 10^{-8}\right)$, both reflecting typical foreperiod effects (Niemi and Näätänen, 1981). Finally, there was an interaction of target SOA with stream SOA $(p=0.014)$, with a stronger effect of target SOA (faster responses as the target SOA is longer) for slow streams compared with fast streams (i.e., a stronger foreperiod effect for slower streams).

\section{Neurophysiology}

Preparatory potentials. As in Experiment 1, a clear CNV was observed in the interval between rhythmic stimuli in all rhythmic conditions (Fig. 3B). In the attend-on-beat condition, the CNV amplitude was more negative for fast streams compared with slow streams $\left(t_{(23)}=2.9, p=0.008\right.$, Cohen's $\left.d=0.6\right)$, reflecting faster CNV buildup as the next event is expected earlier. Crucially, in the attend-off-beat condition the CNV amplitude was again more negative than in the attend-on-beat condition for both fast and slow rhythms (fast rhythm: $t_{(23)}=2.9, p=0.008$, Cohen's $d=0.6$; slow rhythm: $t_{(23)}=2.38, p=0.026$, Cohen's $d=0.5$ ), indicating a faster buildup. Thus, the CNV modulation in shifting resources away from on-beat times does not depend on precisely predictable off-beat times.

Time-frequency analysis. As in Experiment 1, alpha power was reduced after the onset of rhythmic stimuli, followed by alpha rebound back to baseline levels (Fig. 6), but there was no significant preparatory suppression in the attend-off-beat relative to the attend-on-beat condition between rhythmic stimuli $t_{(23)}=$ $-1, p=0.33)$. Thus, although the behavioral results and CNV results indicated that resources were shifted to rhythm-off-beat times, this effect was not expressed in alpha-band oscillations. In contrast, and unlike in Experiment 1, there was significant suppression of beta-band oscillations in central electrodes in the attend-off-beat relative to the attend-on-beat condition between rhythmic stimuli $\left(t_{(23)}=-2.46, p=0.022\right.$, Cohen's $\left.d=0.51\right)$. To verify that this effect is not due to the a priori selection of time and frequency ranges, we applied a cluster-based permutation test (Maris and Oostenveld, 2007), clustering across consecutive points in time or frequency that show a significant difference between the two conditions. Comparison of the $t$ sum statistic of the detected clusters (i.e., the sum of $t$ values of the significant points that constitute the cluster) to a null distribution of $t$ sum values generated by shuffling the labels of the experimental conditions within each subject (10,000 permutations) revealed one significant cluster extending from $\sim 400$ to $1000 \mathrm{~ms}$ and from 14 to $20 \mathrm{~Hz}(p<0.05)$, confirming the results of the a priori window. Thus, shifting resources away from rhythm-on-beat times was expressed in preparatory amplitude adjustments of betaband oscillations when off-beat times were made unpredictable by jittering the expected target time.

\section{Discussion}

Rhythmic streams typically lead to increased preparation at rhythm-on-beat times, even when they are task irrelevant (Jones et al., 2002; Sanabria et al., 2011; Mento et al., 2013; Breska and Deouell, 2014). Shifting resources away from on-beat times was previously demonstrated in primates when another interleaved stream was task relevant (Lakatos et al., 2013; O'Connell et al., 2014). The current study shows that even in the absence of another rhythm to attend or entrain to, the automatic attraction to on-beat times may be overcome when targets are more probable off beat. This was expressed in a behavioral bias against on-beat 

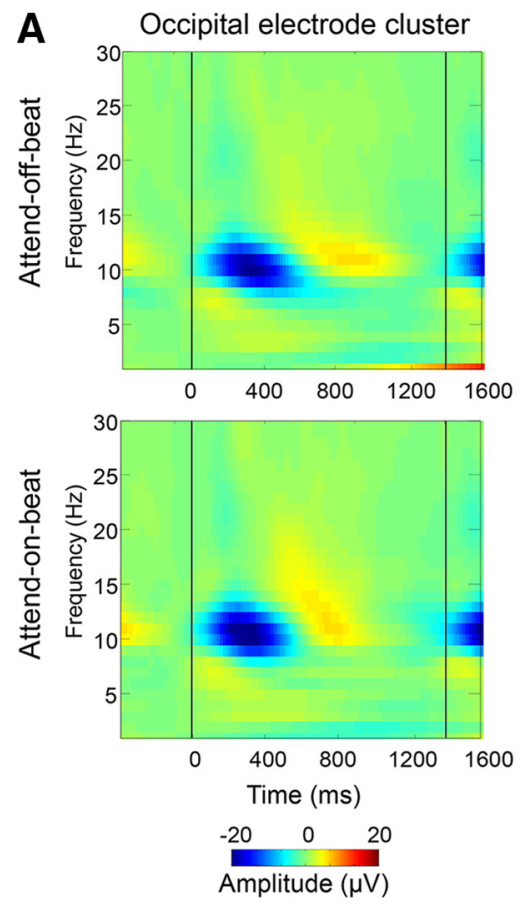

B Occipital electrode cluster
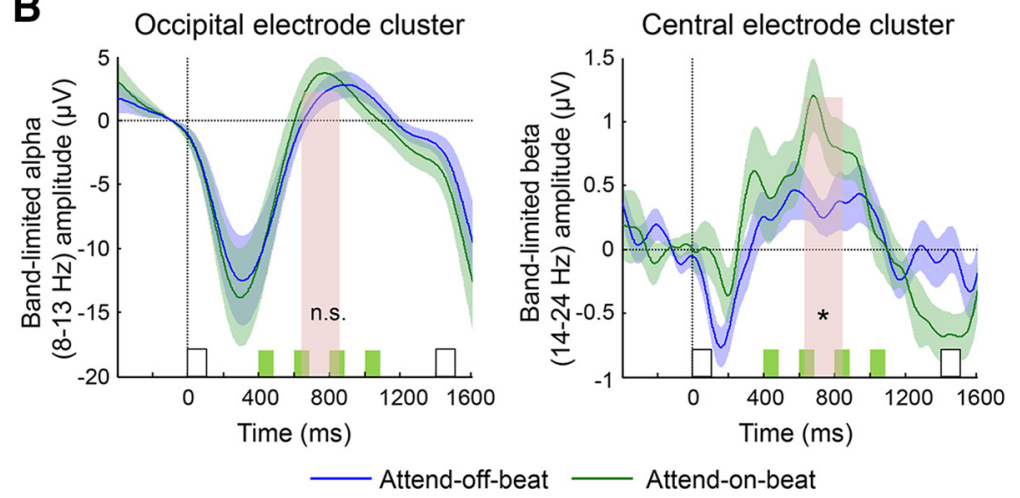

Figure 6. Experiment 2: modulation of beta- but not alpha-band activity by shifting resources away from rhythm-onbeat times to a jittered off-beat time. $\boldsymbol{A}$, Group-averaged time-frequency representations in the two rhythmic conditions (top row, attend-off-beat; bottom row, attend-on-beat), measured in occipital (left column) and central (right column) electrode clusters. Black lines mark the onset of rhythmic stimuli at position $n$ (the last stimulus preceding the target, at time $=850 \mathrm{~ms}$ for fast streams and time $=1400 \mathrm{~ms}$ for slow streams) and at position $n-1$ (at time $=0$ ). $\boldsymbol{B}$, Band-limited amplitude of occipital alpha ( $8-13 \mathrm{~Hz}$, left column) and central beta (14-24 Hz, right column) activity in the attend-offbeat (blue) and the attend-on-beat (green) conditions. White squares mark rhythmic stimuli at positions $n$ and $n-1$. Green squares mark the possible times of off-beat targets. Note that a target was never actually presented in the analyzed interval. Pink shading marks the predefined interval for analysis. Error margins reflect the $S E$ for the difference between the attend-on-beat and attend-off-beat conditions. $\left.{ }^{*} p<0.05\right)$.

times, and in anticipatory adjustment of the CNV potential and beta-band activity toward the relevant off-beat time. Furthermore, whether the target coincided with the rhythm and whether it appeared at the task-relevant time had additive behavioral effects and dissociable effects on target-evoked EEG activity, implying a distinction between goal-directed attention and automatic driving of attention by rhythms.

The behavioral advantage observed for relevant off-beat times over irrelevant on-beat times indicates that the automatic exogenous effect of rhythms does not hinder probability-based resource allocation in time (Trillenberg et al., 2000; observed before in S1-S2 paradigms, Cravo et al., 2011). This supports the idea that resource capture by exogenous cues is a default state of the system that can be overcome, resembling previous findings from the spatial domain (Folk et al., 1992). Comparison to a nonrhythmic control condition enabled separating the effects of relevance-based shifting from hazard effects, which lead to greater costs for unexpectedly early targets than unexpectedly late ones. Comparison to this condition revealed delayed responding at irrelevant times, whether on or off beat, but not facilitated responding at relevant times. This agrees with the idea that rhythmic effects are more about inhibition than facilitation ( $\mathrm{Ng}$ et al., 2012), but of irrelevant times, whether on or off beat, instead of obligatorily of off-beat times.

Anticipatory modulations of the CNV potential and alpha/beta oscillatory activity were previously shown to track the hazard function in S1-S2 paradigms (Trillenberg et al., 2000; Cravo et al., 2011), as well as to anticipate upcoming rhythmic stimuli (Praamstra et al., 2006; Fujioka et al., 2012; Breska and Deouell, 2014). The acceleration of the CNV buildup that we observed when off-beat times were relevant implies that it follows task requirements more than bottom-up rhythm entrainment. The $\mathrm{CNV}$, localized to premotor and supplementary cortices (Macar et al., 1999; Praamstra et al., 2006), is associated with the level of nonspecific preparation for an upcoming event (Praamstra et al., 2006; van Rijn et al., 2011). Under this premise, shifting resources from rhythm on-beat times is principally mediated by the reallocation of nonspecific preparation in time.

The findings of Experiment 1 are seemingly inconsistent with the idea that the CNV reflects low-frequency oscillations that are phase reset by rhythmic stimuli (Schroeder and Lakatos, 2009; Besle et al., 2011), as identical rhythms elicited distinct CNV waveforms. However, as the times of off-beat targets were fixed relative to the rhythm, the $\mathrm{CNV}$ modulation could reflect entrainment to an imagined interleaved rhythmic stream (i.e., one with a constant phase shift from the actual rhythm). Alternatively, rhythmic stimuli could even serve as triggers for interval-timing mechanisms (Gibbon et al., 1984). However, these mechanisms cannot fully explain the similar CNV adjustment observed when off-beat target times were jittered (Experiment 2). Instead, the CNV tracks an integrated level of anticipation based on several sources of temporal predictions (Janssen and Shadlen, 2005; but see van Rijn et al., 2011). Notably, this finding does not reject the possibility of oscillatory entrainment, but only its reflection in the CNV.

Experiment 2 also revealed the modulation of beta-band activity in central sites when shifting resources to rhythm-off-beat times. Beta suppression occurs before an anticipated movement cue (Stancák and Pfurtscheller, 1995; Bastiaansen et al., 1999) 
and putatively reflects increased motor readiness (Jenkinson and Brown, 2011). In goal-relevant rhythms, beta suppression was observed before the next rhythmic stimulus (Alegre et al., 2003; Praamstra et al., 2006) even when not requiring movement (Fujioka et al., 2012). Our findings show that beta-related motor preparation is not bound to rhythmic stimuli times, but can be allocated according to knowledge about relevant times. These findings are consistent with a central role of the motor system, the putative locus of this beta-band suppression, in the perception of and synchronization to rhythms (Merchant et al., 2015). The absence of this effect in Experiment 1 may be explained by a lower signal-to-noise ratio of the suppression effect compared with Experiment 2 , as the required preparation is narrower in time (compare with S1-S2 paradigms with well dispersed intervals; Cravo et al., 2011).

Suppression of alpha-band activity is usually associated with increased perceptual sensitivity (Thut et al., 2006; Gould et al., 2011; Jensen et al., 2012) and was previously observed before or at on-beat times of task-relevant rhythms (Praamstra et al., 2006; Rohenkohl and Nobre, 2011; Breska and Deouell, 2014). The lack of alpha-band suppression before off-beat times in task-adverse rhythms may suggest that perceptual sensitivity is entrained to the rhythm, explaining the residual behavioral effect of rhythm across relevance. However, inference based on a null effect, even if observed in both experiments, should be made with caution. Another possibility is that effortful reallocation of perceptual sensitivity was not necessary, since the task exerted low perceptual demands (Correa et al., 2005). Future studies can address this issue by using a highly demanding perceptual task in task-adverse rhythms.

Previous studies employing task-relevant rhythms reported that whether a target appeared at relevant on-beat or irrelevant off-beat times affected early (the P1 and N1 time windows) and late stages of target processing (the N2 and P3 time windows; Doherty et al., 2005; Correa et al., 2008). We show spatiotemporally dissociated effects of rhythmicity (appearing on beat or off beat) and task relevance (appearing at relevant or irrelevant times) on target processing. Specifically, while both factors affected the later $\mathrm{N} 2$ and $\mathrm{P} 3$, only rhythmicity affected the P1 time window ( $\sim 100 \mathrm{~ms})$. Thus, rhythmicity and task relevance are not merely exogenous and endogenous sources of temporal information that affect the same processes. Instead, distinct stages seem to be affected by stimulus-driven local probabilities and goaldependent relevance based on global knowledge (Corbetta and Shulman, 2002; Wyart et al., 2012).

The P1 potential was larger for on-beat compared with off-beat targets independent of task relevance, which is consistent with modulations of early visual components in previous studies of rhythms (Doherty et al., 2005; Correa et al., 2008; but see Miniussi et al., 1999). This early effect is also consistent with intracranial recording studies that found enhanced neural responses in early sensory regions to rhythm-on-beat stimuli, attributing it to entrainment of lowfrequency oscillations (Lakatos et al., 2008). However, it is unclear whether the rhythm effect observed here is the EEG expression of such enhancement, since the P1 enhancement was in fact the start of a sustained difference between on-beat and off-beat targets that extended beyond the early time window or occipital electrodes. As the off-beat target deviates from a local temporal regularity, the more negative response at occipital sites for the off-beat targets may also reflect a deviance-related response [resembling the visual mismatch negativity (vMMN); Czigler, 2007], although no temporal vMMN has been reported previously. In contrast, the later negativity for off-beat targets is unlikely to be a deviancerelated response, which is typically reflected by larger positivity (P3a; Polich, 2007). Rather, it is consistent with larger P3b for targets at on-beat times.

Targets appearing at irrelevant times elicited more negative $\mathrm{N} 2$ and later P3 compared with targets appearing at relevant times. Phasic N2 enhancement is associated with executive control of conflict, for example, for no-go trials in go/no-go paradigms or for incongruent targets in flanker paradigms (Eimer, 1993; Kopp et al., 1996; Enriquez-Geppert et al., 2010). The P3 is associated with stimulus evaluation, response selection, and motor inhibition (Donchin et al., 1988; Verleger et al., 2005; Enriquez-Geppert et al., 2010). Within this framework, the N2 effect might reflect the need to resolve the conflict between the onset of an imperative stimulus at a time in which responses were not expected, while the P3 effect putatively reflects facilitated response selection for stimuli appearing at relevant times (Doherty et al., 2005; Correa et al., 2008). The restriction of the relevance effect to "postperceptual" stages is consistent with the idea that this effect reflects a highlevel controlled process, determined by the task set and global probability information.

The conclusions of our study, that attraction to rhythm-onbeat times can be mitigated by relevance-based resource shifting, pertain to rhythms in the visual modality. Auditory rhythms were repeatedly shown to exert resource shifting to on-beat times even when task irrelevant (Jones et al., 2002; Sanabria et al., 2011; Henry and Obleser, 2012). Given the superiority of the auditory system over the visual system in temporal processing (Fendrich and Corballis, 2001; Repp and Penel, 2002; Rencanzone, 2003; Grahn et al., 2011), it is possible that resource shifting away from on-beat times of auditory rhythms is more difficult than for visual rhythms or may be mediated by different mechanisms. Future research should compare the automatic and controlled mechanisms of resource shifting in the time between audition and vision.

Synchronizing to rhythms in our environment is often beneficial, but can sometimes be detrimental. The current study shows that despite the pervasive attention capturing the nature of rhythms, they can be used flexibly to organize preparation in time to either on-beat or off-beat times (even when the latter are not sharply defined). This is expressed in several neural manifestations of temporal predictions, including anticipatory modulations of the nonspecific $\mathrm{CNV}$ and motor-related beta activity, implying that these responses are not driven obligatorily by rhythms (compare with entrainment models), but are also under top-down control. The effects of this resource shifting on target processing are behaviorally additive and neurally distinct from the automatic effects of rhythm (Coull and Nobre, 2008). The ability to avoid being enslaved by rhythms when they are detrimental to current goals is essential for efficient interaction with the world.

\section{References}

Alegre M, Gurtubay IG, Labarga A, Iriarte J, Malanda A, Artieda J (2003) Alpha and beta oscillatory changes during stimulus-induced movement paradigms: effect of stimulus predictability. Neuroreport 14:381-385. Medline

Barnes R, Jones MR (2000) Expectancy, attention, and time. Cogn Psychol 41:254-311. CrossRef Medline

Bastiaansen MC, Böcker KB, Cluitmans PJ, Brunia CH (1999) Event-related 
desynchronization related to the anticipation of a stimulus providing knowledge of results. Clin Neurophysiol 110:250-260. CrossRef Medline

Besle J, Schevon CA, Mehta AD, Lakatos P, Goodman RR, McKhann GM, Emerson RG, Schroeder CE (2011) Tuning of the human neocortex to the temporal dynamics of attended events. J Neurosci 31:3176-3185. CrossRef Medline

Brainard DH (1997) The psychophysics toolbox. Spat Vis 10:433-436. CrossRef Medline

Breska A, Deouell LY (2014) Automatic bias of temporal expectations following temporally regular input independently of high-level temporal expectation. J Cogn Neurosci 26:1555-1571. CrossRef Medline

Corbetta M, Shulman GL (2002) Control of goal-directed and stimulusdriven attention in the brain. Nat Rev Neurosci 3:201-215. CrossRef Medline

Correa A, Nobre AC (2008) Neural modulation by regularity and the passage of time. J Neurophysiol 100:1649-1655. CrossRef Medline

Correa A, Lupiáñez J, Tudela P (2005) Attentional preparation based on temporal expectancy modulates processing at the perceptual level. Psychon Bull Rev 12:328-334. CrossRef Medline

Coull JT, Nobre AC (1998) Where and when to pay attention: the neural systems for directing attention to spatial locations and to time intervals as revealed by both PET and fMRI. J Neurosci 18:7426-7435. Medline

Coull J, Nobre A (2008) Dissociating explicit timing from temporal expectations with fMRI. Curr Opin Neurobiol 18:137-144. CrossRef Medline

Cravo AM, Rohenkohl G, Wyart V, Nobre AC (2011) Endogenous modulation of low frequency oscillations by temporal expectations. J Neurophysiol 106:2964-2972. CrossRef Medline

Czigler I (2007) Visual mismatch negativity: violation of nonattended environmental regularities. J Psychophysiol 21:224-230. CrossRef

Di Russo F, Martínez A, Sereno MI, Pitzalis S, Hillyard SA (2002) Cortical sources of the early components of the visual evoked potential. Hum Brain Mapp 15:95-111. CrossRef Medline

Doherty JR, Rao A, Mesulam MM, Nobre AC (2005) Synergistic effect of combined temporal and spatial expectations on visual attention. J Neurosci 25:8259-8266. CrossRef Medline

Donchin E, Coles MGH (1988) Is the P300 component a manifest of context updating. Behav Brain Sci 11:357-374. CrossRef

Eimer M (1993) Effects of attention and stimulus probability on ERPs in a Go/Nogo task. Biol Psychol 35:123-138. CrossRef Medline

Enriquez-Geppert S, Konrad C, Pantev C, Huster RJ (2010) Conflict and inhibition differentially affect the N200/P300 complex in a combined go/nogo and stop-signal task. Neuroimage 51:877-887. CrossRef Medline

Fendrich R, Corballis PM (2001) The temporal cross-capture of audition and vision. Percept Psychophys 63:719-725. CrossRef Medline

Folk CL, Remington RW, Johnston JC (1992) Involuntary covert orienting is contingent on attentional control settings. J Exp Psychol Hum Percept Perform 18:1030-1044. CrossRef Medline

Fujioka T, Trainor LJ, Large EW, Ross B (2012) Internalized timing of isochronous sounds is represented in neuromagnetic beta oscillations. J Neurosci 32:1791-1802. CrossRef Medline

Gibbon J, Church RM, Meck WH (1984) Scalar timing in memory. Ann N Y Acad Sci 423:52-77. CrossRef Medline

Gould IC, Rushworth MF, Nobre AC (2011) Indexing the graded allocation of visuospatial attention using anticipatory alpha oscillations. J Neurophysiol 105:1318-1326. CrossRef Medline

Grahn JA, Henry MJ, McAuley JD (2011) FMRI investigation of crossmodal interactions in beat perception: audition primes vision, but not vice versa. Neuroimage 54:1231-1243. CrossRef Medline

Henry MJ, Obleser J (2012) Frequency modulation entrains slow neural oscillations and optimizes human listening behavior. Proc Natl Acad Sci U S A 109:20095-20100. CrossRef Medline

Janssen P, Shadlen MN (2005) A representation of the hazard rate of elapsed time in macaque area LIP. Nat Neurosci 8:234-241. CrossRef Medline

Jenkinson N, Brown P (2011) New insights into the relationship between dopamine, beta oscillations and motor function. Trends Neurosci 34: 611-618. CrossRef Medline

Jensen O, Bonnefond M, VanRullen R (2012) An oscillatory mechanism for prioritizing salient unattended stimuli. Trends Cogn Sci 16:200-206. CrossRef Medline

Jones MR, Moynihan H, MacKenzie N, Puente J (2002) Temporal aspects of stimulus-driven attending in dynamic arrays. Psychol Sci 13:313-319. CrossRef Medline

Jung TP, Makeig S, Humphries C, Lee TW, McKeown MJ, Iragui V, Sejnowski TJ (2000) Removing electroencephalographic artifacts by blind source separation. Psychophysiology 37:163-178. CrossRef Medline

Kayser SJ, Ince RA, Gross J, Kayser C (2015) Irregular speech rate dissociates auditory cortical entrainment, evoked responses, and frontal alpha. J Neurosci 35:14691-14701. CrossRef Medline

Kiesel A, Miller J, Jolicoeur P, Brisson B (2008) Measurement of ERP latency differences: a comparison of single-participant and jackknifebased scoring methods. Psychophysiology 45:250-274. CrossRef Medline

Kok A (1986) Effects of degradation of visual stimulation on components of the event-related potential (ERP) in go/nogo reaction tasks. Biol Psychol 23:21-38. CrossRef Medline

Kopp B, Rist F, Mattler U (1996) N200 in the flanker task as a neurobehavioral tool for investigating executive control. Psychophysiology 33:282294. CrossRef Medline

Lakatos P, Karmos G, Mehta AD, Ulbert I, Schroeder CE (2008) Entrainment of neuronal oscillations as a mechanism of attentional selection. Science 320:110-113. CrossRef Medline

Lakatos P, Musacchia G, O'Connel MN, Falchier AY, Javitt DC, Schroeder CE (2013) The spectrotemporal filter mechanism of auditory selective attention. Neuron 77:750-761. CrossRef Medline

Macar F, Vidal F (2004) Event-related potentials as indices of time processing: a review. J Psychophysiol 18:89-104. CrossRef

Macar F, Vidal F, Casini L (1999) The supplementary motor area in motor and sensory timing: evidence from slow brain potential changes. Exp Brain Res 125:271-280. CrossRef Medline

Maris E, Oostenveld R (2007) Nonparametric statistical testing of EEG- and MEG-data. J Neurosci Methods 164:177-190. CrossRef Medline

Mathewson KE, Fabiani M, Gratton G, Beck DM, Lleras A (2010) Rescuing stimuli from invisibility: inducing a momentary release from visual masking with pre-target entrainment. Cognition 115:186-191. CrossRef Medline

Mento G, Tarantino V, Sarlo M, Bisiacchi PS (2013) Automatic temporal expectancy: a high-density event-related potential study. PLoS One 8:e62896. CrossRef Medline

Merchant H, Grahn J, Trainor L, Rohrmeier M, Fitch WT (2015) Finding the beat: a neural perspective across humans and non-human primates. Philos Trans R Soc Lond B Biol Sci 370:20140093. CrossRef Medline

Miller J, Patterson T, Ulrich R (1998) Jackknife-based method for measuring LRP onset latency differences. Psychophysiology 35:99-115. CrossRef Medline

Miniussi C, Wilding EL, Coull JT, Nobre AC (1999) Orienting attention in time: modulation of brain potentials. Brain 122:1507-1518. CrossRef Medline

Ng BS, Schroeder T, Kayser C (2012) A precluding but not ensuring role of entrained low-frequency oscillations for auditory perception. J Neurosci 32:12268-12276. CrossRef Medline

Niemi P, Näätänen R (1981) Foreperiod and simple reaction time. Psychol Bull 89:133-162. CrossRef

Nobre A, Correa A, Coull J (2007) The hazards of time. Curr Opin Neurobiol 17:465-470. CrossRef Medline

O'Connell MN, Barczak A, Schroeder CE, Lakatos P (2014) Layer specific sharpening of frequency tuning by selective attention in primary auditory cortex. J Neurosci 34:16496-16508. CrossRef Medline

PelliDG (1997) The VideoToolbox software for visual psychophysics: transforming numbers into movies. Spat Vis 10:437-442. CrossRef Medline

Polich J (2007) Updating P300: an integrative theory of P3a and P3b. Clin Neurophysiol 118:2128-2148. CrossRef Medline

Praamstra P, Kourtis D, Kwok HF, Oostenveld R (2006) Neurophysiology of implicit timing in serial choice reaction-time performance. J Neurosci 26:5448-5455. CrossRef Medline

Rencanzone GH (2003) Auditory influences on visual temporal rate perception. J Neurophysiol 89:1078-1093. CrossRef Medline

Repp BH, Penel A (2002) Auditory dominance in temporal processing: new evidence from synchronization with simultaneous visual and auditory sequences. J Exp Psychol Hum Percept Perform 28:1085-1099. CrossRef Medline

Rohenkohl G, Nobre AC (2011) Alpha oscillations related to anticipatory 
attention follow temporal expectations. J Neurosci 31:14076-14084. CrossRef Medline

Rohenkohl G, Cravo AM, Wyart V, Nobre AC (2012) Temporal expectation improves the quality of sensory information. J Neurosci 32:8424-8428. CrossRef Medline

Sanabria D, Capizzi M, Correa A (2011) Rhythms that speed you up. J Exp Psychol Hum Percept Perform 37:236-244. CrossRef Medline

Schroeder CE, Lakatos P (2009) Low-frequency neuronal oscillations as instruments of sensory selection. Trends Neurosci 32:9-18. CrossRef Medline

Stancák A Jr, Pfurtscheller G (1995) Desynchronization and recovery of beta rhythms during brisk and slow self-paced finger movements in man. Neurosci Lett 196:21-24. CrossRef Medline

Thut G, Nietzel A, Brandt SA, Pascual-Leone A (2006) Alpha-band electroencephalographic activity over occipital cortex indexes visuospatial attention bias and predicts visual target detection. J Neurosci 26:9494-9502. CrossRef Medline

Trillenberg P, Verleger R, Wascher E, Wauschkuhn B, Wessel K (2000)
CNV and temporal uncertainty with "ageing" and "non-ageing" S1-S2 intervals. Clin Neurophysiol 111:1216-1226. CrossRef Medline

Ulrich R, Miller J (2001) Using the jackknife-based scoring method for measuring LRP onset effects in factorial designs. Psychophysiology 38: 816-827. CrossRef Medline

van Rijn H, Kononowicz TW, Meck WH, Ng KK, Penney TB (2011) Contingent negative variation and its relation to time estimation: a theoretical evaluation. Front Integr Neurosci 5:91. CrossRef Medline

Verleger R, Jaskowski P, Wascher E (2005) Evidence for an integrative role of P3b in linking reaction to perception. J Psychophysiol 19:165-181. CrossRef

Walter WG, Cooper R, Aldridge VJ, McCallum WC, Winter AL (1964) Contingent negative variation: and electric signal of sensorimotor association and expectancy in the human brain. Nature 203:380-384. CrossRef Medline

Wyart V, Nobre AC, Summerfield C (2012) Dissociable prior influences of signal probability and relevance on visual contrast sensitivity. Proc Natl Acad Sci U S A 109:3593-3598. CrossRef Medline 